\title{
Development of Integrated Production Scheduling System in the Process Industry
}

\author{
Mohamed K. Omar, Yasothei A.P. Suppiah and Siew C. Teo \\ Faculty of Engineering and Technology Melaka Campus \\ Centre of Computer Aided Design and Knowledge Manufacturing (CCADKM) \\ Multimedia University, Jalan Ayer Keroh Lama, 75450 Melaka, Malaysia
}

\begin{abstract}
This study introduces a three-level hierarchical production planning and scheduling approach developed and implemented in a resin factory. Our approach proposes at the first level a mixed-integer linear programming for solving the aggregate planning model. At the second level, a weighted-integer goal-programming model is developed to disaggregate the developed aggregate plans. A sequencing algorithm is developed for the third level that tends to minimize the total weighted tardiness. Real industrial data is used to test and validate the proposed models.
\end{abstract}

Key words: Hierarchical Production Planning (HPP), Integration, Integer Programming, Goal Programming, Tardiness

\section{INTRODUCTION}

This study presents a planning and scheduling approach developed by the authors for a multiple products single machine production system based on a resin manufacturing company. Our formulation of the planning and scheduling approach reflects the basic characteristics, which will be addressed by this study when we provide our detailed formulation.

A study of the literature on frameworks for planning and scheduling reveals that basically there are two approaches available to solve production planning and scheduling problems. A monolithic approach that determines planning and scheduling decisions in a single level for the entire planning horizon, making it extremely hard to obtain optimal solutions for industrial planning problems. While the HPP approach recognizes the hierarchy nature of the process and considers the interaction between the strategic and tactical level decisions, Hax and Meal [1], Hax and Golovin [2], Bitran et al. [3] are the major pioneers in the development of the HPP models. In these contributions, the hierarchical structure consists of decision making at three levels. The decision is made at the aggregate-type level, then these decisions are disaggregated into families and family decisions are disaggregated further into items. Industrial applications of HPP are also reported by number of researchers, Oliff and Burch [4], Leong et al. [5], Venkataraman and Smith [6] and most recently Qiu and Burch [7], Das et al. [8] and Omar et al. [9]. There is a large body of literature from the early 1950 s dealing with sequencing and scheduling issues. As for jobs sequencing scheduling, the problem of minimizing the total weighted tardiness is strongly NP-hard which is proved by Lawler [10] and Lenstra et al. [11]. Potts and Van
Wassenhove [12] gave a branch and bound algorithm for this problem whereas Schrage and Baker [13] gave a dynamic programming algorithm to solve this problem. Lawler [14] also gave an algorithm that solves the problem of maximum weighted tardiness.

Our goal is to build upon previous research and develop a framework that can answer our research questions. We consider a single machine problem with multiple products and periods in the presence of setups whenever production is changed from one production family to another. We propose a HPP structure that consists of three levels.

The proposed HPP integrate Aggregate Production planning (APP) model, Disaggregate Production planning (DPP) model and Job Sequencing Model (JSM). Hereafter, we introduce next the research environment, followed by the mathematical model formulation, model validation and conclusions.

Research Environment: This study deals with a planning and scheduling problem, arising in the process industry. The plant of interest produces a variety of resin products, which are ultimately used for the paint manufacturing industry. The company produces over 100 finished products. These products are divided into twenty families, 10 products for Family 1-5 respectively, 8 products for Family 6-10 respectively and 1 product for Family 11-20 respectively. The plant operates with two production lines. Products compatibility criteria is observed and considered as a planning constraint since changing from one product family to another involves significant cleaning time and setup costs. Therefore management practices product families dedication in which one line is dedicated to Family 1-3 and the second production line dedicated to Family 4-20. Working capacity is 1048 tons and 
495 tons per month for line one and line two respectively. These estimates are based on bottleneck known as filling equipment. Production department operates on three shifts, 7 days a week. The monthly available maximum storage capacity is about 2480 tons. Workforce involved on the production is very limited due the characteristics of the manufacturing environment, each shift requires 9 persons to run the plant and therefore, workforce stability exists and the company does not practice workforce variations policies. The management adopts chase demand strategy and strives to avoid inventory of finished products. Likewise, stiff competition limits the firm's ability to adjust delivery dates for confirmed orders. This situation leads to a very high level of plant utilization giving the production manager no alternative but to allow backordering of unfulfilled demands. Thus, the production planning and scheduling problem can be stated as follows: Which products to make in which periods and the exact production sequence that meet customers' due date. Next, the mathematical models that will answer these questions are presented.

Model Formulation: There are three levels in this model. The first level is the aggregate planning level where it is formulated as a mixed integer-programming problem where total costs of production, inventory, setup and workforce are being minimized.

\section{AGGREGATE PLANNING}

Decision Variables:

$\mathrm{P}_{\text {itl }}=$ Production level of product family $i$ during period $t$ in production line $l$.

$\mathrm{I}_{\text {itl }}=$ Inventory level of product family $i$ at the end of period $t$ in production line $l$.

$\mathrm{W}_{\mathrm{tl}}=$ Regular workforce level in period $t$ in production line $l$.

$\phi_{\text {itl }}=$ Binary setup variable for product family $i$ during period $t$ in production line $l$.

$\phi_{\mathrm{itl}}=1$ if $P_{\mathrm{itl}}>0 ; \phi_{\mathrm{itl}}=0$ if $P_{\mathrm{itl}}=0$

\section{Parameters:}

$N=$ Total number of product family.

$H=$ Length of planning Horizon.

$Z_{i t}=$ Unit production cost for family $i$ in period $t$.

$V_{i t}=$ Production setup cost for family $i$ in period $t$;

$\mathrm{h}_{i t}=$ Unit inventory holding cost for family $i$ in period $t$.

$k_{t}=$ Regular workforce cost in period $t$.

$D_{i t l}=$ Net demand for product family $i$ in period $t$ in production line $l$.

$(S C)_{t l}=$ Maximum storage capacity in period $t$ in production line $l$.

$Q_{t l}=$ Capacity available for production line $l$ in period $t$. $P_{i l \text { max }}=$ Maximum batch size for product family $i$ in production line $l$.

$P_{i l \text { min }}=$ Minimum batch size for product family $i$ in production line $l$. $a_{i l}=$ Unit process time for product family $i$ in production line $l$.

$b_{i l}=$ Production setup time required for product family $i$ in production line $l$.

$T R_{t}=$ Total Regular time available in period $t$.

$$
\begin{aligned}
\operatorname{Min} \sum_{i=1}^{N} \sum_{t=1}^{H} \sum_{l=1}^{2}\left[\left(Z_{i t} P_{i t l}+V_{i t} \phi_{i t l}\right)\right] & +\sum_{i=1}^{N} \sum_{t=1}^{H} \sum_{l=1}^{2} h_{i t} I_{i t l} \\
& +\sum_{l=1}^{2} \sum_{t=1}^{H} k_{t} W_{t l}
\end{aligned}
$$

Subject To

$$
\begin{gathered}
D_{i t l}=P_{i t l}+I_{i, t-1, l}-I_{i t l} \quad \forall i, t, l \\
\sum_{i=1}^{N} I_{i t l} \leq(S C)_{t l} \quad \forall t, l \\
\sum_{i=1}^{N} P_{i t l} \leq Q_{t l} \quad \forall t, l \\
P_{i t l} \leq P_{i l \max } \phi_{i t l} \quad \forall i, t, l \\
P_{i t l} \geq P_{i l \min } \phi_{i t l} \quad \forall i, t, l \\
\phi_{i t l}=0 \quad \phi_{i t l}=1 \quad \forall i, t, l \\
\sum_{i=1}^{N}\left[a_{i l} P_{i t l}\right]=W_{t l} \quad \forall t, l \\
W_{t l}+\sum_{i=1}^{N}\left[b_{i l} \phi_{i t l}\right] \leq T R \quad \forall t \\
P_{i t l}, I_{i t l}, W_{t l} \geq 0
\end{gathered}
$$

Equation (1) is the objective function which minimizes the sum of production cost, setup cost, inventory cost and workforce cost. Constraint (2) is the basic inventory identity relationship for each product family, which calls for the demand to be fulfilled by the production or inventory for each period at each production line. Constraint (3) is to ensure that the total inventory does not exceed the storage capacity available for each period at each production line. Constraint (4) ensures that total production for each period does not exceed the production line capacity. Constraints (5) and (6) ensures that the production for each period should not exceed the maximum batch size and is greater than the minimum batch size for each product family at each production line. Constraint (7) is the binary variable for the setup for each product family in that period. Constraint (8) is the regular workforce level in that period. Constraint (9) ensures that the regular workforce capacity for each period is sufficient for production and setup activities. Constraint (10) represents the non-negativity constraints. 


\section{DISAGgREGATE PLANNING}

Inputs from Aggregate Planning Model:

$P_{i t l}=$ Desired production level of product family $i$ during period $t$ in production line $l$.

$I_{i t l}=$ Desired inventory level of family $i$ at the end of period $t$ in production line $l$.

$W_{t l}=$ Desired regular workforce level in period $t$ in production line $l$.

Decision Variables

$P_{i k t l}=$ Number of units of item $k$ of product family $i$ in production line $l$ to be produced in period $t$.

$I_{i k t l}=$ Number of units of inventory of item $k$ of product family $i$ in production line $l$ at the end of period $t$.

$B_{i k t l}=$ Backorder level of item $k$ of product family $i$ in production line $l$ at the end of period t.

$\phi_{i k t l}=$ Binary setup variable for item $k$ in production line $l$.

$\phi_{i k t l}=1$ if $P_{i k t l}>0 ; \quad \phi_{i k t l}=0 \quad$ if $P_{i k t l}=0$

$d_{i t l}^{1+}=$ Over production of product family $i$ in production line $l$ in period $t$.

$d_{i t l}^{1-}=$ Under production of product family $i$ in production line $l$ in period t.

$d_{i t l}^{2+}=$ Over achievement of the desired aggregate inventory level of product family $i$ in period $t$.

$d_{i t l}^{2-}=$ Under achievement of the desired aggregate inventory level of product family $i$ in period $t$.

$d_{t l}^{3-}=$ Under-time used in period $\mathrm{t}$ in production line $l$.

Parameters

$N=$ Total number of product family.

$H=$ Length of planning Horizon.

$K=$ Total number of items.

$c b_{i k t}=$ Backorder cost for item $k$ in family $i$ in period $t$.

$(S C)_{t l}=$ Maximum storage capacity in period $t$ in production line $l$.

$Q_{t l}=$ Capacity available for production line $l$ in period $t$.

$P_{i k l \text { max }}=$ Maximum batch size for item $k$ of product family $i$ in production line $l$.

$P_{i k l \text { min }}=$ Minimum batch size for item $k$ of product family $i$ in production line $l$.

$a_{i k l}=$ Unit process time required to produce one unit of item $k$ of family $i$ in production line $l$.

$D_{i k t l}=$ Forecast demand for item $k$ of product family $i$ for production line $l$ in period $t$.

$c_{1}, c_{2}, c_{3}=$ Weight assigned (as penalty cost) to each unit of $d_{i t l}^{1+}, d_{i t l}^{2-}$ and $d_{t l}^{3-}$ respectively.

$$
\begin{aligned}
\operatorname{Min} \sum_{i=1}^{N} \sum_{t=1}^{H} \sum_{k=1}^{K} \sum_{l=1}^{2} c b_{i k t} B_{i k t l} & +\sum_{i=1}^{N} \sum_{t=1}^{H} \sum_{l=1}^{2} c_{1} d_{i t l}^{1+} \\
& +\sum_{i=1}^{N} \sum_{t=1}^{H} \sum_{l=1}^{2} c_{2} d_{i t l}^{2-}+\sum_{t=1}^{H} \sum_{l=1}^{2} c_{3} d_{t l}^{3-}
\end{aligned}
$$

Subject To

$$
\begin{gathered}
\sum_{k=1}^{K} P_{i k t l}+d_{i t l}^{1-}-d_{i t l}^{1+}=P_{i t l} \quad \forall i, t, l \\
\sum_{k=1}^{K} I_{i k t l}+d_{i t l}^{2-}-d_{i t l}^{2+}=I_{i t l} \quad \forall i, t, l \\
\sum_{i=1}^{N} \sum_{k=1}^{K}\left(a_{i k l} P_{i k t l}\right)+d_{t l}^{3-}=W_{t l} \quad \forall t, l \\
D_{i k t l}=P_{i k t l}+I_{i k, t-1, l}-I_{i k t l}+B_{i k t l}-B_{i k, t-1, l} \quad \forall i, k, t, l \\
\sum_{i=1}^{N} \sum_{k=1}^{K} I_{i k t l} \leq(S C)_{t l} \quad \forall t, l \\
\sum_{i=1}^{N} \sum_{k=1}^{K} P_{i k t l} \leq Q_{t l} \quad \forall t, l \\
P_{i k t l} \leq P_{i k l \max } \phi_{i k t l} \quad \forall i, k, t, l \\
P_{i k t l} \geq P_{i k l \min } \phi_{i k t l} \quad \forall i, k, t, l \\
\phi_{i k t l}=0 \quad \forall i, k, t, l \\
\phi_{i k t l l}, I_{i k t l}, B_{i k t l}, d_{i t l}^{1+}, d_{i t l}^{1-}, d_{i t l}^{2+}, d_{i t l}^{2-}, d_{t l}^{3-} \geq 0
\end{gathered}
$$

Equation (11) gives the objective function that aims to minimize the sum of the backordering costs, penalty costs of over production, under achievement of inventory levels and under utilization of regular time. The relative cost penalties are addressed by assigning weights $c_{1}, c_{2}, c_{3}$ at each respective goal. Equations (12), (13) and (14) gives the goal constraints representing aggregate production target level, aggregate inventory level and aggregate workforce target level. Equations (15), (16) and (17) defines system constraints and present material balance, storage limitations and capacity limitations. Equations (18) and (19) ensures that that the production for each period should not exceed the maximum batch size and is greater than the minimum batch size for each product item. Equation (20) enforces the binary variable for the setup for each production item in each period. Equation (21) represents the non-negativity constraint.

\section{SHOP FLOOR SCHEDULING}

Once the disaggregate plans are developed at the second level and monthly optimal decisions are obtained that include end items production level, inventory levels and backorders levels, the next step is to provide a mean to sequence these optimal quantities. Prior to development of the job-sequencing schedule, end items are converted into set of batches. Hence, the sequencing problem would be defined as: given a set of optimal batches that needed to be sequenced on a single machine. Having two independent production lines and 
assuming that there is no idle time inserted jobs are processed without pre-emption on a continuously available machine, which can handle only one job at a time. An algorithm to generate near optimal sequence has been developed with the objective to minimize total weighted tardiness. First the notations are introduced and then the algorithm in pseudo-code is presented in Fig. 1.

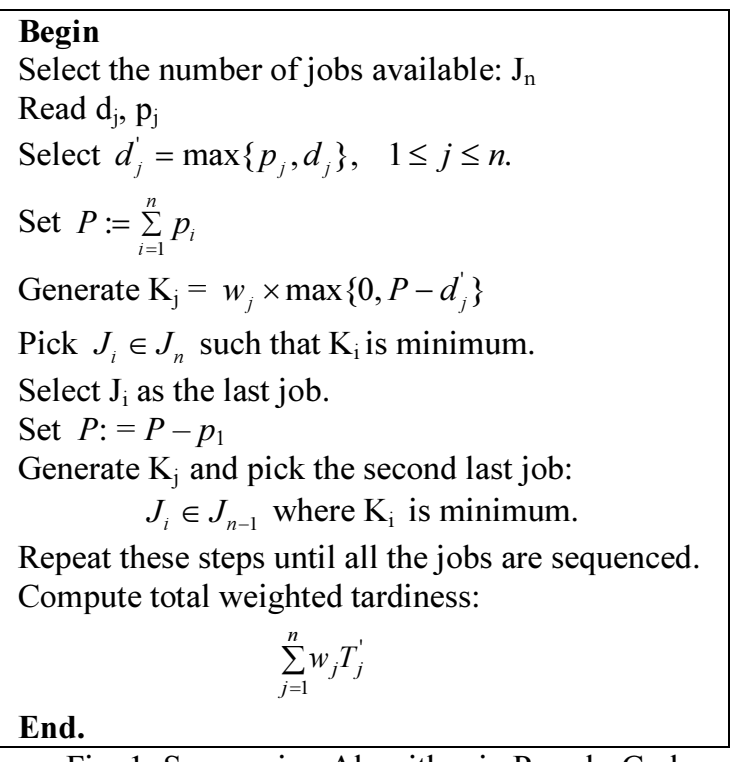

\section{Notation}

$d_{i}^{\prime}=$ Modified due date of job $i$

$d_{\mathrm{i}}=$ Due date of job $i$

$p_{i}=$ Processing time of job $i$

$w_{\mathrm{i}}=$ Tardiness penalty of job $i$

$J_{\mathrm{i}}=$ Job $i$

$T_{i}^{\prime}=\max \left\{0, C_{i}-d_{i}^{\prime}\right\}=$ Tardiness value of job $J_{\mathrm{i}}$.

$C_{\mathrm{i}}=$ Completion time of job $i$.If the current job $i$ processed in the sequence comes from a different family from the preceding job $i-1$, then $C_{\mathrm{i}}=C_{\mathrm{i}-1}+p_{\mathrm{i}}+1$ since 24 hours ( 1 day) is needed for the setup time.

\section{MODEL VALIDATION AND RESULTS}

Although developing the proposed hierarchal model using the firm's historical data (demand) has been tested and the results suggest that our proposed model provides superior results in terms of operation costs, in this section we introduce our validation methodology.

The validation revolves around the question which states: how the developed model will react to uncertainty that is deep rotted in the demand which is the most crucial input? To answer this question, a methodology developed which consists of first examining the firm's past sales and determining every individual product statistical summary, using the products mean(s) and standard deviation(s) and MS
Excel random generation function, six-demand distribution were created. The different demand distribution possibilities investigated: (i) A normal distribution; (ii) A normal distribution skewed to the left; (iii) A normal distribution skewed to the right; (iv) A uniform distribution; (v) A uniform distribution skewed to the left and (vi) A uniform distribution skewed to the right. The mathematical model for the first two levels were written in OPL studio version 3.6 based on [15] and CPLEX solver version 8.0, is used to solve both the first and second level model. The third level algorithm was written in Visual Basic 6.0 programming language. All models were executed using Pentium IV, 128MB RAM.

For 6 months planning horizon, optimal results obtained for the aggregate plans for all 100 products consists of 772 decisions variables and 428 constrains and it took about 6.42 seconds to generate global optimal solution. Table 1 shows the results for family 11 .

For 3 months planning horizon, optimal results obtained for the disaggregate plans for all 100 products consists of 2486 decisions variables and 1238 constrains and it took about 11.53 seconds to generate global optimal solution. Table 2 shows the results for end item 57 .

The sequence that the third model developed as results of the input from the second level model for a normal distributed demand is presented next, while Fig. 1 shows the Gantt chart for the job sequencing for line 1 .

Line 1: (12 jobs):1,4,5,12,2,8,10,3,6,7,22,9

Line 2: (23 jobs):31,55,88,56,96,93,57,92,58,97,99,54, $91,63,95,98,51,53,73,79,94,41,100$

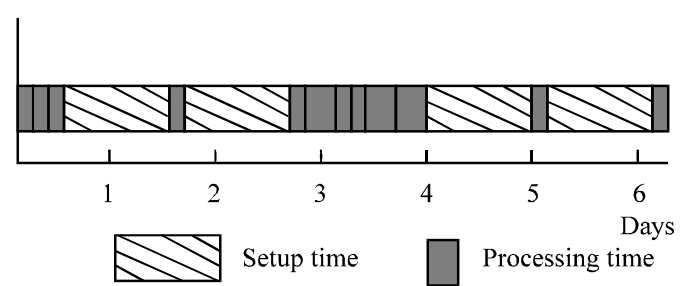

Fig. 2: Gantt Chart for Normal Distribution Line 1

\section{CONCLUSION}

We have presented a hierarchical framework approach for a multi-products multi-periods batch chemical environment production planning and scheduling problem. The proposed model integrates and coordinates planning and scheduling decisions on three managerial levels. Aggregate planning was formulated as a mixed integer linear programming model in order to handle situations with setup cost and non-zero setup time. The disaggregation of the first level was achieved by using a weighted integer goal programming approach to ensure that optimal solution at the first level are attained at the second level in terms of optimality. An algorithm was adopted at the third level that minimizes total weighted tardiness. The 
Table 1: Optimal Solution for Family 11 for a Demand Generated from Normal Distribution

\begin{tabular}{lrrrrrr}
\hline Family 11 & Jan & Feb & Mar & Apr & May & June \\
\hline Demand & 4783 & 3067 & 4721 & 3141 & 3423 & 5097 \\
Production Level Line 1 & & & & & & \\
Production Level Line 2 & 8000 & 0 & 8000 & 0 & 8232 & 0 \\
Total Production Level & 8000 & 0 & 8000 & 0 & 8232 & 0 \\
Begin Inventory & 0 & 3217 & 150 & 3429 & 288 & 5097 \\
Ending Inventory & 3217 & 150 & 3429 & 288 & 5097 & 0 \\
\hline
\end{tabular}

Table 2: Optimal Solution for Product 57 for a Demand Generated from Normal Distribution

\begin{tabular}{lrrr}
\hline ITEM 57 & Jan & Feb & Mar \\
\hline Demand & 7288 & 12303 & 19125 \\
Production Level Line 1 & & & \\
Production Level Line 2 & 8046 & 9206 & 21464 \\
Total Production Level & 8046 & 9206 & 21464 \\
Begin Inventory & 0 & 758 & 0 \\
Ending Inventory & 758 & 0 & 0 \\
Begin Back order & 0 & 0 & 2339 \\
Ending Backorder & 0 & 2339 & 0 \\
\hline
\end{tabular}

computational study indicates that our approach perform well when the number of products and periods are fairly large. From the managerial prospective this property is desirable. Currently our proposal is being compared with the performance of the company and the initial results are encouraging in terms of enhancement of the decision quality. One issue that we think it is important for future research, which improves the proposed algorithm to include further features to deal with setups that make the jobs sequencing more realistic.

\section{REFERENCES}

1. Bitran, G.R. and A.C. Hax, 1977. On the Design of Hierarchical Production Planning Systems. Decision Sciences, 8: 28-55.

2. Hax, A.C. and J.J. Golovin, 1978. Hierarchical Production Systems. In Studies in Operation Management, (Edited by Hax, A.C.), North Holland, Amsterdam, pp: 400-427.

3. Bitran, G.R., E.A. Haas and A.C. Hax, 1981. Hierarchical Production Planning: a Single System. Operation Research, 29: 717-743.

4. Oliff, M.D. and E.E. Burch, 1985. Multi-Product Production Scheduling at Owens-Cor. Fiberglas. Interfaces, 15: 25-34.

5. Leong, G.K., M.D. Oliff and R.E. Markland, 1989. Improved Hierarchical Production Planning. J. Operations Management, pp: 90-114.
6. Venkataraman, R. and S.B. Smith, 1996. Disaggregation to a Rolling Horizon Master Production Schedule with Minimum Batch-Size Production Restrictions. Intl. J. Production Res., pp: 1517-1537.

7. Qui, M.M. and E.E. Burch, 1997. Hierarchical Production Planning and Scheduling in a MultiProduct, Multi-Machine Environment. Intl. J. Production Res., 35: 3023-3042.

8. Das, B.P., J.G. Richard, N. Shah and S. Macchietto, 2000. An Investigation on Integration of Aggregate Production Planning, Master Production Scheduling and Short-Term Production Scheduling of Batch Process Operations Through a Common Data Model. Computers and Chemical Eng., pp: 1625-1631.

9. Omar, M.K., S.C. Teo and Y. Suppiah, 2003. An Integrated Framework for Production Planning and Scheduling for a Single Stage Multi-Product Batch Chemical Process. In Proceedings of $38^{\text {th }}$ annual conference ORSNZ'03, OR: Making a Difference in Practice, University of Waikato, Hamilton, NZ, pp: 129-138.

10. Lawler, E.L., 1977. A Pseudopolynomial Algorithm for Sequencing Jobs to Minimize Total Tardiness. Annals of Discrete Mathematics, pp: 331-342.

11. Lenstra, J.K., A.H.G. Rinnooy Kan and P. Brucker, 1977 Complexity of Machine Scheduling Problems. Annals of Discrete Mathematics, pp: 343-362.

12. Potts, C., L.Van Wassenhove, 1985. A Branch and Bound Algorithm for the Total Weighted Tardiness Problem. Operations Res., pp: 363-377.

13. Schrage, L. and K.R. Baker, 1978. Dynamic Programming Solution of Sequencing Problems with Precedence Constraints. Operations Res., pp: 444-449.

14. Lawler, E.L., 1973. Optimal Sequencing of a Single Machine Subject to Precedence Constraint. Management Science, pp: 544-546.

15. Van Hentenryck, P., 1999. The OPL Optimisation Programming Language, The MIT Press, Cambridge, Mass. 